where signify

$l$ the depth of the cylinder.

$t$ the time of the experiment.

$c_{1}$ the concentration of the salt solution before the experiment.

$c_{2}$ the mean concentration of the solution after the experiment. $D$ the coefficient of diffusion.

\$ 2.-Chloride of sodium was the substance experimented with to test the method. Three solutions were prepared, of which the first contained $0^{\circ} 66487$, the second 5.8506 , and the third 17.695 parts by weight of the anhydrous salt in 100 parts of the solution. The cylinders employed were 2 to $8 \mathrm{~cm}$. in diameter, and 3.45 to $5^{.} 036 \mathrm{~cm}$. in depth. The experiments were conducted either in such a way that all the cylinders were filled with the same solution, and the observation made if the cross-cut and the depth of the cylinder had influenced the final result ; or else differently concentrated solutions were taken, and the experiment carried out at exactly the same temperature and under the same other conditions. The method was found to be sensitive and accurate. The temperature being $8.5^{\circ} \mathrm{C}$., and the duration of the experiment $6^{\circ} 5$ hours, the coefficient found was :-

$$
\begin{aligned}
& \text { With a solution of } 0.66487 \text { per cent.... } \\
& \left."=\begin{array}{lcccc}
\prime \prime & 5.8506 & \prime & \ldots & 808 \\
17.695 & , & \ldots & 889
\end{array}\right\} \times 10-8 \frac{\mathrm{cm}^{2}}{. \mathrm{sec} .}
\end{aligned}
$$

The conclusion to be drawn from these numbers is that coefficient of diffusion within the limits of time and concentration indicated decreases according to the law of the straight line as the quantity of salt in solution.

From this result follow :-

I. The numerical value of the coefficient at the same temperature, and the same initial concentration depends upon the duration of the experiment.

2. A fixed state, in which the concentrations in the fluid decrease from bottom to top, according to the law of the straight line, is impossible. Fick's method, which presupposes this state, cannot therefore give correct results.

From the above-mentioned law of the dependence of the coefficient of diffusion on the quantity of salt in solution, and from the first conclusion, it follows that at one and the same tempera ture the value of the coefficient may vary between two widely separated limits. An experiment performed with a saturated solution during the shortest possible time would furnish the one limit, another with a solution containing a quantity of salt approximating to zero would give the other.

The physical cause and the necessity for the mentioned dependence is very simple. If a volume of water be mixed with one volume of concentrated salt-solution, and if a volume of water be mixed with a volume of dilute salt-solution, the resulting contraction in the first instance is greater than in the second. The diffusion of a salt-solution in water has been up to the present considered from a very one-sided point of view. Berthollet and Fick ascribe the diffusion to the forces alone which act between water and salt-solution; modern investigators ascribe it solely to the molecular velocity of the fluid molecules. The experiment shows that the diffusion depends on both, and therefore supports neither of these views entirely. When the cylinder has been filled with concentrated solution the participation of the molecular forces is greater than in the case of weak solution. The numerical value of the coefficient of diffusion, which expresses the result of the experiment, must necessarily be greater in the first case than in the latter. It is therefore in our power to regulate the phenomena of diffusion in a salt solution according to our will; thus when we experiment with concentrated solutions the principal agents at work are the molecular forces, whilst the velocity of the molecules plays the chief part in dilute solutions. The coefficient of diffusion of a salt-solution loses, therefore, entirely the signification of a constant, because in every special case it has another value.

\$3. The coefficients of diffusion of salt solutions in water at the temperature of $10^{\circ} \mathrm{C}$., determined by Graham, Fick, Weber, and Schuhmeister, form a group of numbers which lie between 0.000010 and $0.000002 \frac{\mathrm{cm}^{2}}{\mathrm{sec} \text {. }}$.

It was of great interest to ascertain the value of the coeffi. cient of diffusion when the quantity of salt is so small that it can neither be estimated with the balance nor with chemical means; when, in short, the solution differs hardly at all from pure water, and when the participation of molecular forces has been brought to a minimum. Such an experiment may be made by tinting water with a salt of great tinctorial power and observing the diffusion of the coloured water into the pure. It is much more difficult to follow these experiments quantitatively, as very small quantities have to be determined. Colorimetrical methods are not sensitive enough.

I therefore tried to measure the concentration photometrically. Nigrosin, which is sufficiently stable towards sunlight, was the colouring matter chosen for the purpose. Hüfner's spectro-photometer was employed. The water was coloured with nigrosin to such an extent that its coefficient of extinction for sodium light amounted to $\mathbf{r}^{*} 343$. The quantity of colouring matter used was so small that the change of specific gravity in the water through its addition could not be ascertained.

A full report of the many difficulties which were encountered and a detailed description of how the experiments were conducted will be found in the above mentioned Wiedemann's Annalen. It was discovered that the coefficient of diffusion was smaller by one decimal place than the smallest known coefficient of a salt.

The method here described urges the investigation of a fseries of new problems.

In the first place the value of the coefficient must be ascertained for different salts when the salt in solution approximates zero. When these values have been found, only then it will be possible to define in what way the coefficient of diffusion depends on the nature of the salt.

Secondly, it is necessary to find out if it is not possible, by tinting water with different colouring-matters, to obtain a constant, which I propose-analogously to a case already considered by J. Clerk Maxwell-to call the coefficient of diffusion of a fuid into itself.

If we suppose a room to be divided into two parts by a movable wall and filled with the same gas at the same pressure and temperature, and we then remove the wall, a diffusion of the gas takes place from the one half of the room to the other, and vice versa, in consequence of molecular velocity. The coefficient of the diffusion which takes place here, Maxwell calls the coeficient of diffusion of a gas into itself. It is not measurable, as the molecules of a gas cannot be marked. It can how ever be calculated from the coefficient of viscosity of this particular gas kinematically measured by multiplying by $r^{*} 5435$.

When salt-solution diffuses, it is not the salt, but the saltsolution, which diffuses into water. The more dilute the solution, the nearer that state is approached in which pure water diffuses into pure water. How near I have approached this state in $m y$ experiments with nigrosin I have no means at present to judge. I have no doubt however that this is the only method of ascertaining the coefficient, which, if once determined in similar manner for every fluid, will be of eminent importance to a kinetic theory of fluids, which has yet to be built up. It is only necessary to bear in mind the assistance rendered to Max. well by the determination of the coefficients of diffusion of gases by Loschmidt.

S. WROBLEWSKI

\section{THE ROTATIONAL CO-EFFICIENT IN VARIOUS METALS}

THE following is an abstract of a Note on the above subject read by Prof. E. H. Hall at the meeting of the British Association at York.

It was discovered two years ago in Johns Hopkins University that when a conductor carrying a current is placed in a magnetic field, the direction of whose force is perpendicular to the current, the current is deflected at right angles to the force and to the original direction of the current. A slip of gold leaf on glass was placed between the poles of Faraday's electro-magnet, with the faces of the gold-leaf perpendicular to the lines of force. Wires were attached one at each end of the strip, for the purpose of transmitting a current through it, and two other wires were led from the middle points of the sides of the strip to a Thomson's galvanometer. When the electro-magnet was not made this galvanometer showed no deflection, but on sending a current through the coil of the electro-magnet a deflection was obtained, and on reversing the direction of this current the deflection was reversed.

Dr. Hopkinson has pointed out that Maxwell, in the first part of his book, treating this subject in the most general way, allows the possibility that something of this kind may take place. Maxwell suggests the name "rotational coefficient"; so the 
term which I employ is his, though the fact was not known to him.

I have published an article describing these experiments, which may be known to you, but I have since found some new facts. At Berlin I tested some metals which I had not tried before. I cannot vouch for the quantities within 50 per cent., but I think I can vouch for the direction of the effect. It is not the same for different metals under the same conditions of current and magnetic force. It might have been expected that the effect would be in the same direction in nickel as in iron ; but it is not, it is in the opposite direction ; nickel acts like gold, cobalt acts like iron. Nickel, silver, gold, platinum, and tin gave an effect opposite to iron.

The most important fact that $I$ have to bring before you is that in zine the effect is in the same direction as in iron and cobalt. Table of effects on an arbitrary scale.

\begin{tabular}{|c|c|c|c|c|c|c|c|c|}
\hline Iron & & & & & & & & \\
\hline Cobal & $\cdots$ & $\cdots$ & $\cdots$ & +78 & Brass $\ldots$ & $\cdots$ & & $-r \cdot 3$ \\
\hline Zinc & & $\cdots$ & ... & +25 & Platinum & ... & $\cdots$ & 2.4 \\
\hline Zinc & $\cdots$ & $\cdots$ & ... & $+\quad 15$ & Gold ... & $\ldots$ & $\ldots$ & $6 \cdot 8$ \\
\hline Lead & $\ldots$ & $\ldots$ & $\ldots$ & - & Silver ... & $\ldots$ & $\ldots$ & - \\
\hline Tin & $\ldots$ & $\ldots$ & $\cdots$ & +0.2 & Copper. & $\ldots$ & $\ldots$ & - IO \\
\hline & & & & & Aluminiun & & $\cdots$ & \\
\hline & & & & & Nickel & & $\cdots$ & \\
\hline
\end{tabular}

The deflection of the current in those marked + is in the same direction in which the conductor itself tends to move in the magnetic field. I cannot vouch for the order of the metals. I have tried three specimens of nickel, and the direction was the same in them all. One of them was pure nickel, furnished me by Prof. Chandler Roberts.

The following remarks were marle by the chairman, Sir William Thomson :-

The subject of this communication is by far the greatest discovery that has been made in respect to the electric properties of metals since the times of Faraday-a discovery comparable with the greatest made by Faraday. I look upon it with special interest myself as so closely connected with electrodynamic properties of metals, which formed the subject of my Bakerian Lecture in 1856 . I pointed out in that paper, in about $\$ 104$, that it was to be expected that magnetic induction would produce change of thermal conductivity and of electric conductivity in different directions in substances perfectly isotropic. I found by mathematical investigation rotational terms, and pointed out that we might expect in bodies which have rotational quality to find the effect of such terms exhibited. But the only influence having that relation to rotation which was necessary for producing the terms in question I pointed out to be the influence of a magnet, and that we might expect that the effect of a magnet upon an isotropic body would be to induce difference of quality in different directions in accordance with the rotatory term, and I said I thought it improbable that the rotatory terms would be found to be null in a body subjected to the influence of a magnet. I look with great delight on Prof. Hall's discovery, as having verified that which I predicted as probable. I did not myself make any serious attempt to discover it. It is the first illustration ever brought out by experiment of one of the most curious and interesting things in the mathematics of æolotropy. The previous mathematical writers dismissed these terms altogether, although they found them in the formula:-dismissed them as something which we could not imagine to exist. I refused to disniss them, and said there was decided reason that they could exist under the rotational influence which we know to belong to a magnet.

Prof. Rowland said : Mr. Hall had tried the direction of rotation of the plane of polarisation when light is reflected from nickel and iron on Dr. Kerr's plan. The direction was found, if he remembered aright, to be in opposite directions for these two metals. We did not yet know enough to say whether this investigation explains the rotation of the plane of polarisation of light.

Prof. Sylvanus Thompson said he had verified Prof. Hall's result by using a telephone instead of a galvanometer.

Mr. Glazebrook said he had published a paper on the same subject in connection with the rotation of the plane of polarisation of light. Maxwell said this effect (rotation of the plane of polarisation by reflection from a magnet) could be explained by molecular rotation of the particles in the field.

Prof. Fitzgerald asked Sir William Thomson to express an opinion as to how it happens that different substances differ in the direction of this effect. He also remarked that the terms expressing the magnetic force on the matter were the same as those which would express Prof. Hall's observed effect on the current. Was the action to be regarded as an action on the matter or on the current?

Prof. Everett asked whether the current in its deflected condition was oblique (instead of, as usual, normal) to the equipotential
surfaces?

Sir William Thomson, in reply, said that effect on matter and effect on the current through it went together, and could not be distinguished. He could not say why the effect in any particular metal was in one direction rather than the other. There was nothing in the mathematical theory to show in which metals it should be in the same direction. Prof. Everett's question might be answered by referring to several corresponding cases. If heat was flowing from end to end of a bar cut obliquely from a crystal, the points of equal temperature in two opposite sides would not in general be exactly opposite to each other. The foundation of the general theory of which this was an illustration had been laid by Prof. Stokes.

\section{UNIVERSITY AND EDUCATIONAL INTELLIGENCE}

OXford.-On November 3 Sir William Anson, Bart. D.C.L., Fellow and Sub-Warden, was elected Warden of Ail Souls' College in succession to Dr. Leighton, deceased. Sir William Anson was Vinerian Reader in English Law.

A Fellowship at University College will be offered for competition about the end of next February. The examination will be in biology and kindred subjects. At the last examination for a Biological Fellowship none of the candidates were judged of sufficient merit, and the election was accordingly deferred.

Candidates for the Brackenbury Natural Science Scholarship at Balliol College must communicate with the Master by letter on or before Friday, November II. Papers will be set in Chemistry, Mechanics and Physics, and in Biology. There will also be an optional paper in Mathematics, and an essay.

At Christ Church there will be one or more Natural Science Junior Studentships elected next March. Candidates must not have exceeded the age of twenty on January I, I882. Papers will be set in Chemistry, Biology, and Physics, but no candidate will be allowed to offer himself in more than two of these subjects.

CAmbridge.-On Monday, November 7, Mr. J. E. Marr, F.G.S., was elected to a Fellowship at St. John's College. In 1 $878 \mathrm{Mr}$. Marr obtained a First Class in the Natural Sciences Tripos; in 1879 he received a grant from the University to enable him to travel in Bohemia and study the Cambrian and Silurian rocks there; also in I 880 he went in a similar manner to Norway and Sweden. His paper on the Rocks of Bohemia was published in the Quarterly Fournal of the Geological Society for November 1880 . He is at present lanturing for the University at Parrow Kendal, and Lancaster.

Glasgow.-Mr. John Macalister Dodds, B.A., Fellow of St. Peter's College, Cambridge, 4th Wrangler, 1880 , has been appointed one of the assistants to Dr. Jack, Professor of Mathematics in the University of Glasgow. Mr. Dodds was a distinguished Glasgow student hefore proceeding to Cambridge. All the four Professors of Mathematics and Natural Philosophy in the Universities of Edinburgh and Glasgow-Prof. Tait, Prof. Chrystal, Prof. Sir William Thomson, and Prof. Jackare Peterhouse men.

\section{SCIENTIFIC SERIALS}

The American Naturalist for September and October, 1881, contains (No. 9, vol. xv.): Carl F. Gessler, variations in a copepod crustacean (woodcuts).-A. S. Packard, jun., Scolopendrella and its position in nature (places Symphyla as a suborder of Thysanura).-W. H. Dall, American work in the department of recent mollusca in $1880 .-D$. G. Brinton, notes on the Codex Troano and Maya chronology.

No. Io, vol. xv. : D. H. Campbell, on the development of the stomata of Tradescantia and Indian corn (woodcuts). Cyrus Thomas, the age of the manuscript Troano.-J. Walter Fewkes, the Physophoridx (iii.).- - R. E. Cull, the Loess in Central Iowa.-A. S. Packard, jun., on the early stages of the 